\title{
Regulation Possibilities of Biomass Combustion
}

\author{
Vera Suzdalenko ${ }^{1}$, Martins Gedrovics ${ }^{2}{ }^{1,2}$ Institute of Energy Systems and Environment, Riga Technical University, \\ Maija Zake ${ }^{3}$, Inesa Barmina ${ }^{4}{ }^{3,4}$ Institute of Physics, University of Latvia
}

\begin{abstract}
The focus of the recent experimental research is to analyze the regulation possibilities of biomass combustion. Three possibilities were chosen as part of this research: a) biomass cofiring with propane, b) swirling flow with re-circulation zone, and c) use of a permanent magnet. The aim of the research is to provide stable, controllable and effective biomass combustion with minimum emissions. The special pilot device was created where biomass can be combusted separately and co-fired with propane. Wood pellets were used during the experiments.
\end{abstract}

Keywords - co-firing, gradient magnetic field, propane, recirculation zone, swirling flow, wood pellets

\section{INTRODUCTION}

There are two compelling forces that drive global interest in using renewable energy resources for energy supply:

1. Environmental effects of fossil fuel [1]. Combusting fossil fuels results in an intensive formation and release of airborne pollutants $\left(\mathrm{NO}_{\mathrm{x}}, \mathrm{SO}_{\mathrm{x}}, \mathrm{CO}_{2}\right)$ into the Earth's atmosphere with direct impact on public health and the Earth's climate [2]. There are ongoing debates about nuclear energy use after the 2011 tragedy in Japan, where happen explosion at Fukushima nuclear power plant after earthquake and tsunami.

2. Increasing anxiety regarding the security and durability of fossil fuel resources [1]. Compared with biomass, which is geographically widely available, fossil fuels are concentrated in just a few countries [3] and [4].

Worldwide, biomass provided $3.5 \%$ of the world's final energy consumption in 2006. This index is growing steadily and biomass in 2010 ranked fourth place as an energy resource, providing $14 \%$ of the world's final energy consumption [5] and [6]. Mostly biomass is used in developing countries, because it is cheap and easily available fuel; besides application technologies are simple [3] and [7]. At the same time, these combustion technologies are not so effective, having problems concerning emissions.

\section{A. Biomass combustion}

The biomass combustion involves a number of general processes:

- Heating-up and drying;

- Pyrolysis: biomass + heat $\rightarrow$ charcoal, gases $(\mathrm{CO}$, $\left.\mathrm{CO}_{2}, \mathrm{H}_{2}, \mathrm{H}_{2} \mathrm{O}\right)$, tars. The biomass is heated in absence of air up to about $350^{\circ} \mathrm{C}$.

- Gasification: biomass + limited oxygen ( $\alpha$ is about $0.25) \rightarrow$ fuel gas $\left(\mathrm{CO}, \mathrm{CO}_{2}, \mathrm{H}_{2}, \mathrm{CH}_{4}, \mathrm{~N}_{2}\right)$

- Combustion: biomass + stoichiometric oxygen $\rightarrow$ hot combustion products [3], [6], [8] and [9].
The emissions which form during biomass combustion can be grouped in two categories: pollutants from complete combustion $\left(\mathrm{CO}_{2}, \mathrm{NO}_{\mathrm{x}}, \mathrm{SO}_{\mathrm{x}}, \mathrm{HCl}\right.$, heavy metals and $\left.\mathrm{PM}\right)$ and pollutants from incomplete combustion (CO, polyaromatic hydrocarbons and volatile organic compounds and $\mathrm{NH}_{3}$ ) [3], [6] and [7].

\section{B. Parameters that influence emissions of biomass combustion}

The type and amount of emissions from biomass combustion depends on some factors that can be divided into two main groups:

1. Type of biomass (chemical composition) and its physical properties (particle size and shape, moisture content, density etc.);

2. Application technologies where biomass was combusted.

TABLE 1

COMPOSITION FOR A DIFFERENT TYPE OF BIOMASS, \% [3]

\begin{tabular}{l|l|l|l|l|l|l|l|}
\hline Fuel & $\boldsymbol{C}$ & $\boldsymbol{H}$ & $\boldsymbol{O}$ & $\boldsymbol{N}$ & $\begin{array}{l}\boldsymbol{S} \\
\text { and } \\
\boldsymbol{C l}\end{array}$ & $\boldsymbol{W}$ & Ash \\
\hline $\begin{array}{l}\text { Wood pine } \\
\text { chips }\end{array}$ & 52.0 & 6.2 & 41.59 & 0.12 & $\begin{array}{l}0.08 \\
0.01\end{array}$ & 4.0 & 0.1 \\
$\begin{array}{l}\text { Wheat } \\
\text { straw }\end{array}$ & 49.23 & 5.78 & 43.99 & 0.64 & $\begin{array}{l}0.1 \\
0.26\end{array}$ & 7.78 & 6.3 \\
Lignin & 72.0 & 6.6 & 21.34 & 0 & $\begin{array}{l}0.0 \\
0.0\end{array}$ & 9.0 & 16.0 \\
Cellulose & 44.4 & 6.17 & 49.3 & 0 & $\begin{array}{l}0.0 \\
0.0\end{array}$ & 4.1 & 1.7 \\
\hline
\end{tabular}

The biomass composition contains lower proportions of : potassium $(\mathrm{K})$, sodium $(\mathrm{Na})$, magnesium $(\mathrm{Mg})$, calcium $(\mathrm{Ca})$, phosphorous (P), and some heavy metals [7].

The composition of biomass depends not only on the type of biomass but also on the growth processes, growing conditions (sunlight, geographic location), age of trees, trees distance from sources of pollutants (cities, factories etc.) [4].

Biomass fuel can be combusted in different types of application technologies that differ from each other by capacity: household heating (1-10 $\left.\mathrm{kW}_{\mathrm{th}}\right)$, fixed bed combustors (up to $5 \mathrm{MW}_{\text {th }}$ ), moving grate (up to $100 \mathrm{MW}_{\text {th }}$ ), fluid bed (up to $500 \mathrm{MW}_{\text {th }}$ ), pulverized fuel/suspension firing and co-firing (up to $900 \mathrm{MW}_{\text {th }}$ ). All combustion applications release pollutants, the amount of which depends on a lot of factors. There are some optimization possibilities that influence the formation of pollutants: mixing of air and fuel in the combustion chamber, residence time, combustion temperature, heat transfer mechanisms, etc. [1].

The purpose of the recent research is to analyze three regulation possibilities of biomass combustion with the aim to 
provide stable, controllable and effective biomass combustion with minimum emissions:

1. Biomass co-firing with fossil fuel (propane). Co-firing is a combustion process when two or more fuel types are combusted in the same application. There is a growing interest in biomass and fossil fuel co-firing. Substituting fossil fuel with biomass is a very effective way to reduce $\mathrm{CO}_{2}$ emissions [10].

2. Swirling flow effect with formation of re-circulation zone on biomass combustion.

3. The use of a non-uniform magnetic field. The researches Nagaraju K. and Swaminathan S. have found that the presence of magnetic fields have caused significant changes in diffusion flame behavior, such as changes in radiative emissions from the flame, changes in flame shapes and sizes [11] and [12].

\section{EXPERIMENTAL PILOT DEVICE}

The experimental research of the regulation possibilities of biomass combustion was carried out using the specially constructed pilot device with a maximum capacity of $3 \mathrm{~kW}$. The pilot device is composed of a wood fuel gasificator (1), sections of water-cooled combustor (2), inlets (3) and outlets (4) of cooling water flow (Fig. 1).

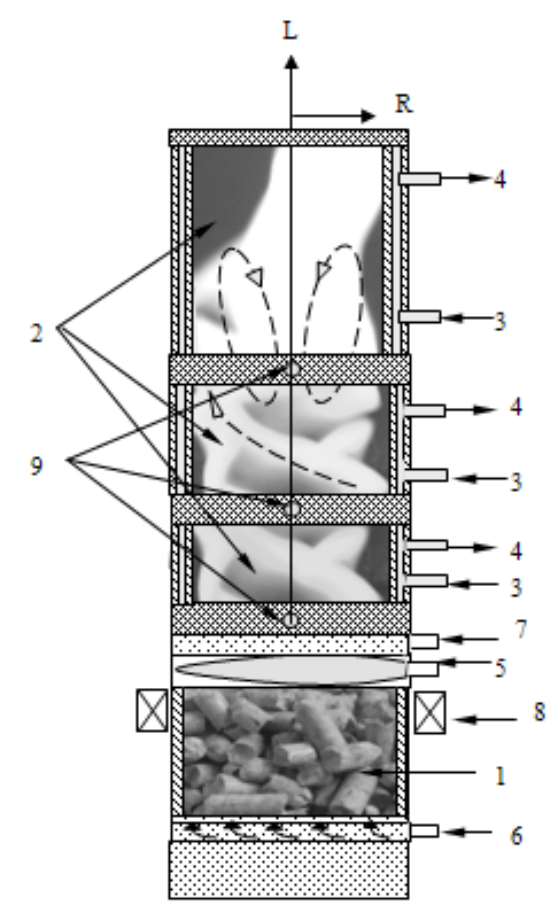

Fig. 1. Pilot scale-up: 1 - wood fuel gasifier, 2 - water-cooled combustor, 3 inlets of cooling water flow, 4 - outlets of cooling water flow, 5 - propane burner, 6 - nozzle of primary air supply, 7 - nozzle of secondary air flow, 8 permanent magnets, 9 - diagnostic sections.

The diameter of the pilot device is $60 \mathrm{~mm}$, but the total length $\mathrm{L}$ of the device can be varied up to $700 \mathrm{~mm}$. During the experiments, discrete doses $(320 \mathrm{~g})$ of wood pellets were combusted. According to measurements, the moisture content of used wood pellets does not exceed 6-8\%.

\section{A. Wood pellets co-firing with propane}

Wood pellet co-firing with fossil fuel propane was carried out by using a propane burner (5). The burner initiates the gasification of wood pellets and completes the burnout of volatiles. The propane supply rate was adjusted in the range from 1.0 to $1.25 \mathrm{~kJ} / \mathrm{s}$. During the experiments the emission levels, and the efficiency from wood pellets and propane cofiring with self-sustaining wood pellets combustion (without propane supply) were compared.

\section{B. Swirling flow formation}

The air in the pilot device was supplied in two places: primary air was supplied below the pelletized wood layer (6) and its rate was varied from $401 / \mathrm{min}$ to $551 / \mathrm{min}$, the secondary air was supplied above the propane burner (7) and its rate was varied from $70 \mathrm{l} / \mathrm{min}$ to $100 \mathrm{l} / \mathrm{min}$. Both the primary and secondary airflows were supplied by a compressor and were injected through tangential inlets. The aim of the primary air flow is to initiate wood pellet gasification, while the secondary air flow provides the gradual mixing of the swirling air flow with the flow of volatiles and gradual burnout of the volatiles.

\section{Magnetic field}

To provide an experimental study of the magnetic field effect on wood pellet combustion, a permanent magnet (8) with 2 couples of poles was placed between the propane burner and the primary airflow close to the bottom of the combustor. The permanent magnet provides a relatively weak field with a mean axial field gradient up to $\mathrm{dB} / \mathrm{dz}=0.8-1.0$ $\mathrm{mT} / \mathrm{m}$, fixed close to the walls of the combustor.

The complex measurements for providing the investigation of regulation possibilities for wood pellet combustion were done by using diagnostic sections (9). The following measurements were provided:

- The measurements of the axial and tangential velocity of flame compounds by using the Pitot tube.

- The measurements of the flame temperature by using $\mathrm{Pt} / \mathrm{Pt}-\mathrm{Rh}$ thermocouples.

- The measurements of the flame composition $\left(\mathrm{O}_{2}, \mathrm{CO}\right.$, $\mathrm{CO}_{2}, \mathrm{NO}, \mathrm{NO}_{\mathrm{x}}$ and $\mathrm{NO}_{2}$ ) and combustion efficiency were performed using the gas analyser Testo $350 \mathrm{XL}$.

The data registration was carried out with time interval of 1 sec.

\section{RESULTS AND DISCUSSION}

\section{A. Wood pellets co-firing with propane without magnetic field effect}

Previous experiments [2] have shown that the formation of a swirling flame flow is closely connected with the primary and secondary air supply rates determining the swirl intensity. The air swirl number $(\mathrm{S})$ during experiments was in a range of 0.8-1.0. Figure 2-a,b illustrates the formation of a wellpronounced central re-circulation zone. The primary air supply rate was varied in a range of $40-551 / \mathrm{min}$, but the secondary air supply rate varied in a range of $70-901 / \mathrm{min}$. The peak of the 
tangential $\left(\mathrm{v}_{\mathrm{tg}}\right)$ and axial $\left(\mathrm{v}_{\mathrm{ax}}\right)$ velocities was detected close to the channel walls. The non-zero values of the axial flow velocity recorded near the axis of the combustor are determined by the influence of the primary air supply at the bottom part of the gasifier and can be increased by increasing the primary air supply, penetrating through the layer of the wood pellets and the central re-circulation zone. The formation of the flow field structure near the outlet of the secondary air is developing at a high level of turbulence, providing the variations of Reynolds number in a range of 3000-10000. The higher turbulence levels, determining a mixing of the flame compounds at the initial stage of the flow field formation, are fixed in the inner shear layer of the velocity gradients by decreasing the primary air supply in the bottom part of the gasifier below $50 \mathrm{l} / \mathrm{min}$.
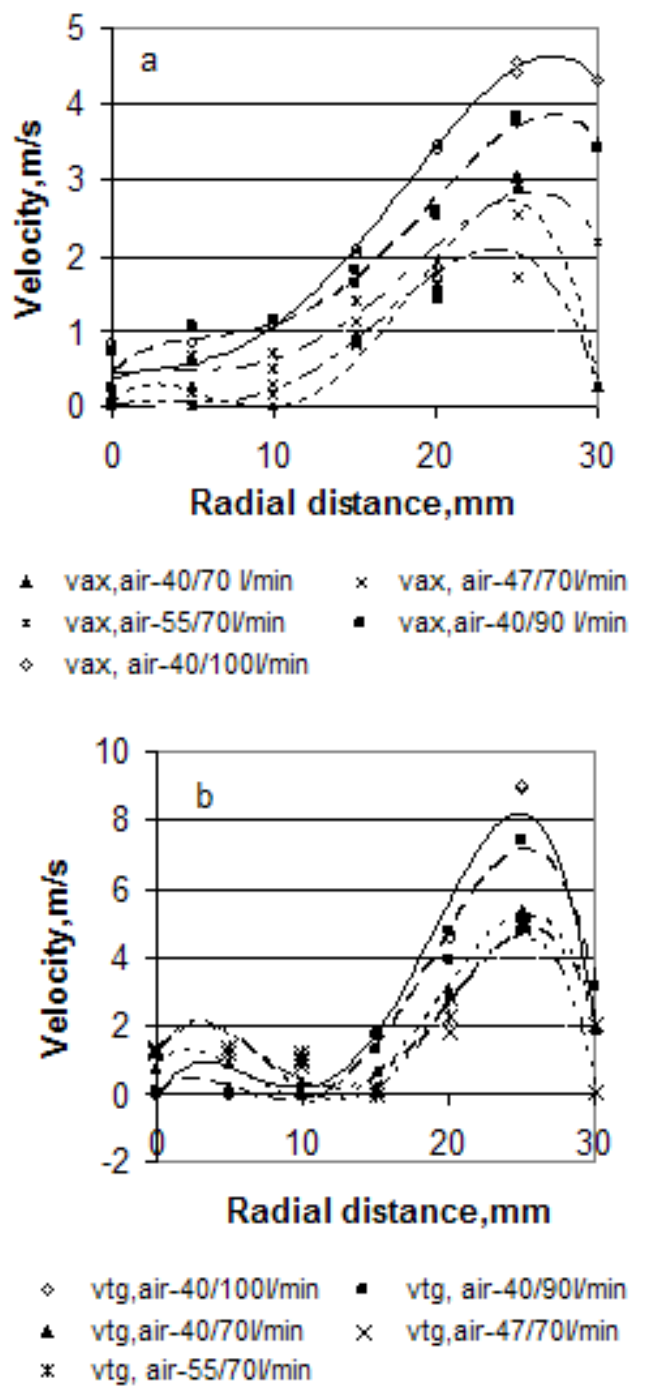

Fig. 2. The influence of the primary and secondary air supply rates on the axial (a) and tangential (b) velocity profiles.

The formation of the central re-circulation zone near the outlet of the gasifier promotes an enhanced mixing of the flame compounds and determines the formation of a reverse axial heat/mass transfer up to the pelletized wood layer thus enhancing the wood fuel heating, gasification and burnout of volatiles.

During the experimental research, the propane flame flow was injected above the wood pellet layer and below the secondary air supply. The propane flame flow provided an additional heat energy supply at a rate of $1.25 \mathrm{~kJ} / \mathrm{s}$. The injection of the propane flame into the upper part of wood pellets initiated its gasification and the burnout of volatiles.

The effect of the propane co-fire with wood pellets on the flame temperature and the rate of heat energy production is shown in Figure 3-a,b. As follows from Figure 3-a, the supply of propane provided a faster rate of the flame temperature rise up to the peak value, increasing the temperature of the flame reaction zone by $150-200 \mathrm{~K}$.
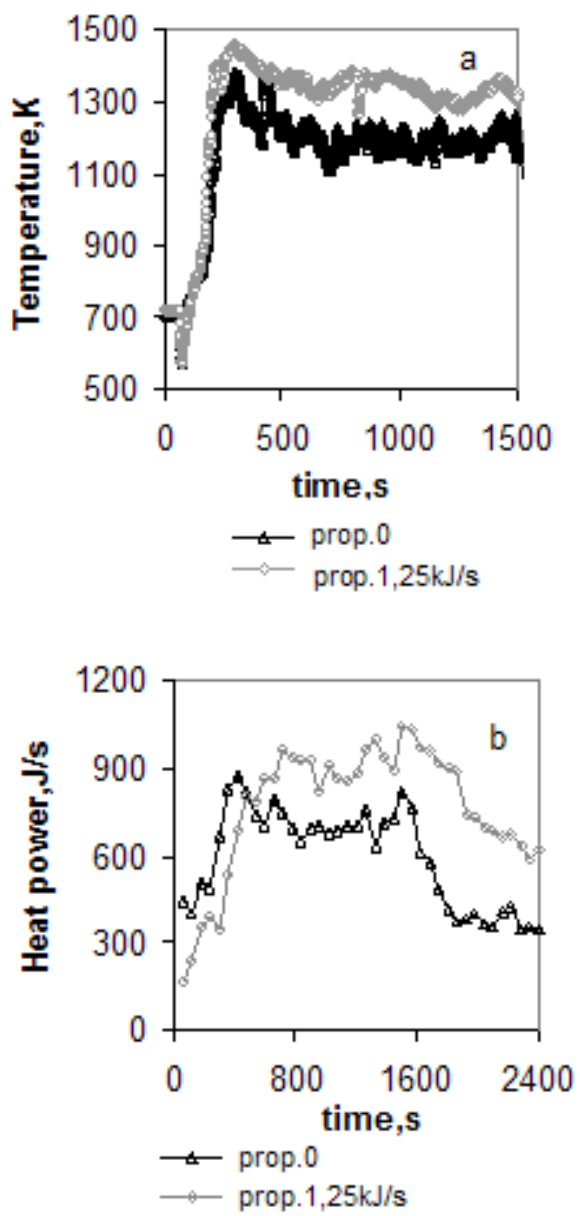

Fig. 3. The changes of temperature (a) and heat production rate (b) for selfsustaining wood pellet combustion (prop. $=0$ ) and for wood pellets and propane co-fire.

Upon comparing the heat production rate $(\mathrm{J} / \mathrm{s})$ for the wood pellet and propane co-firing process with the self-sustaining wood pellet combustion (Fig. 3-b), it was estimated that the produced heat energy increased up to $30-35 \%$ when co-firing wood pellets with propane. When wood pellets were combusted without the propane flame supply, the average rate of its burnout did not exceed $0.135-0.1400 \mathrm{~g} / \mathrm{s}$, while the 
average rate for the co-firing process (propane supply rate $=$ $1.25 \mathrm{~kJ} / \mathrm{s}$ ) was approximately $0.3 \mathrm{~g} / \mathrm{s}$.

The measurements of the flame composition profiles at different rates of propane co-fire confirm that the peak value of $\mathrm{CO}_{2}$ and $\mathrm{CO}$ is detected close to the flame axis at $\mathrm{r} / \mathrm{R}<0.3$ (Fig. 4-a,b).
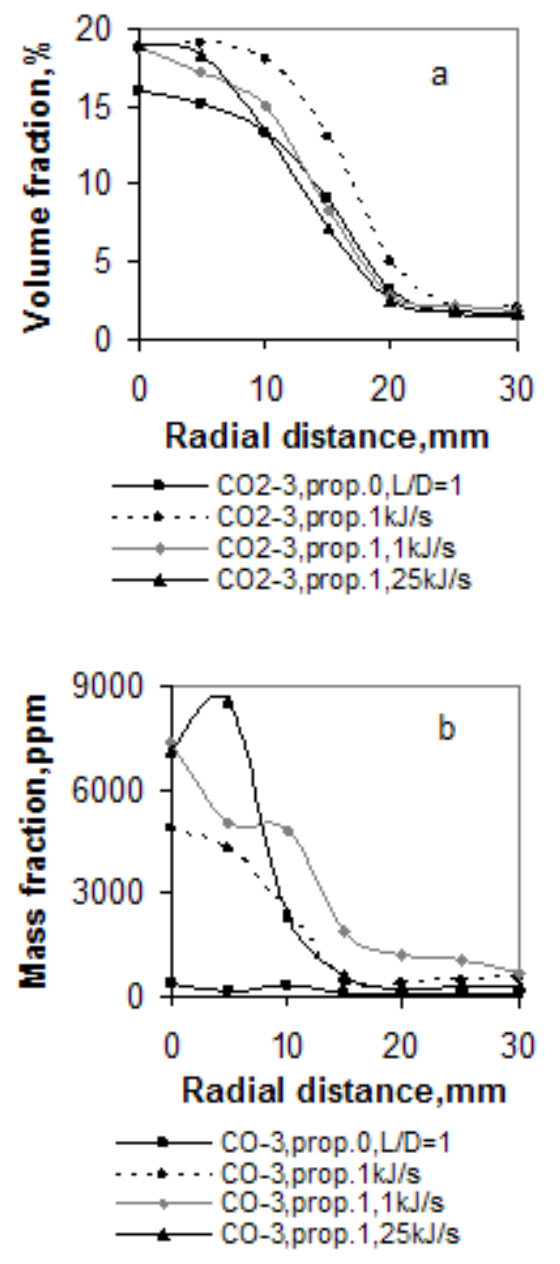

Fig. 4. The effect of propane co-fire on the formation of $\mathrm{CO}_{2}$ (a) and $\mathrm{CO}$ (b) profiles ( 3 for $\mathrm{t}=700-900 \mathrm{~s}$ ).

The peak value of $\mathrm{CO}_{2}$ correlates with an increase in the combustion efficiency and a decrease in air excess (Fig. 5).
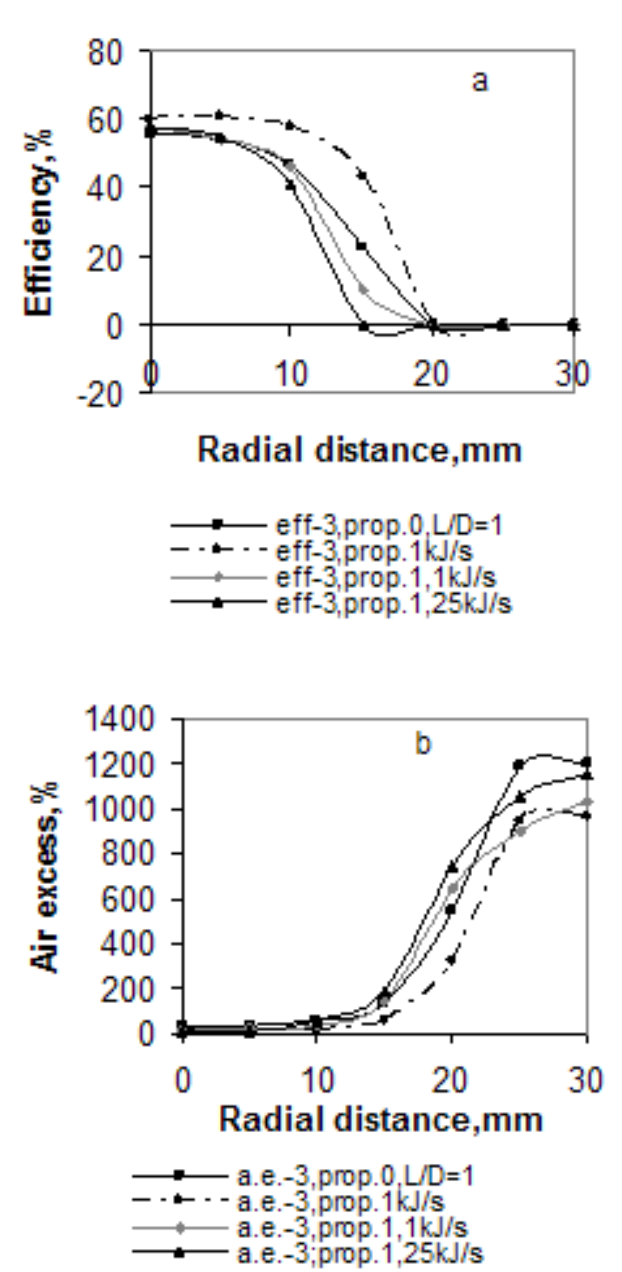

Fig. 5. The effect of propane co-fire on efficiency (a) and air excess (b) (3 for $\mathrm{t}=700-900 \mathrm{~s})$.

As follows from Figure 6, during wood pellet and propane co-firing there is a slight increase of $\mathrm{NO}_{\mathrm{x}}$ emissions compared with self-sustaining wood pellets combustion. This can be explained by the fact that the temperature is higher during the co-firing process.

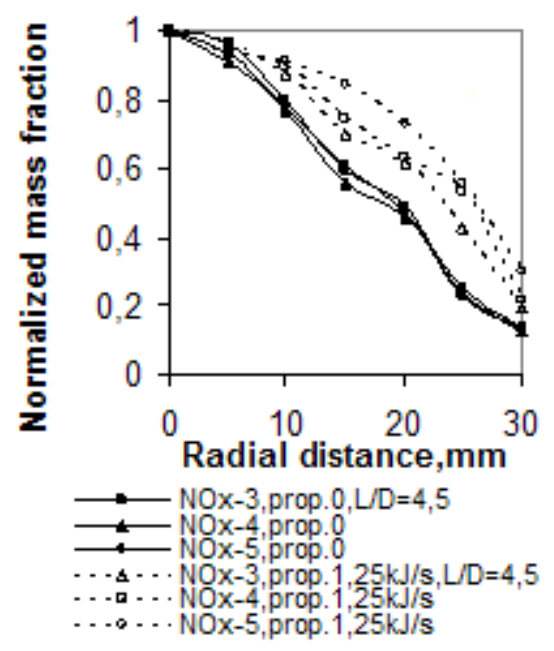

Fig. 6. The effect of propane co-fire on the formation of NOx mass fraction (3 for $\mathrm{t}=700-900 \mathrm{~s}, 4: \mathrm{t}=900-1100 \mathrm{~s}, 5: \mathrm{t}=1100-1300 \mathrm{~s}$ ). 
At the same time, the peak value of the NOx mass fraction during the co-firing process is relatively low and does not exceed $100 \mathrm{ppm}$, but the average value does not exceed 60-70 ppm.

\section{B. Magnetic field control of combustion process $(B=1)$}

To conduct investigation about the magnetic field control of the combustion process of wood pellets, the upper part of the gasifier was inserted into the magnetic field that was created by permanent magnets producing a non-uniform, downstream decreasing magnetic field along the flame reaction zone with a mean axial magnetic field gradient $\mathrm{dB} / \mathrm{dz} \approx 0,8-1 \mathrm{~T} / \mathrm{m}$. During these experiments, the primary air was supplied at a rate of 38 $1 / \mathrm{min}$, but the secondary air - at $701 / \mathrm{min}$.

Figure 7-a,b illustrates the effect of the magnetic field on the axial and tangential velocity profiles, that is more pronounced close to the airside part of swirling flame.

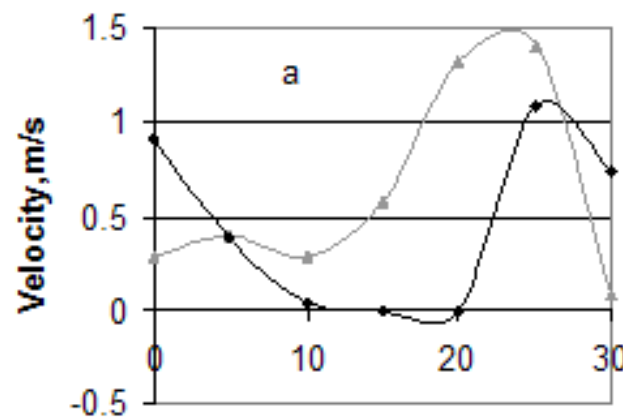

\section{Radial distance,mm}

$\longrightarrow$ vax $-4, B=0$,prop $0,83 \mathrm{~V} / \mathrm{min}, \mathrm{L}=115 \mathrm{~mm}$ $\longrightarrow$ vax-4,B,prop. 0,83Vmin, L=115mm

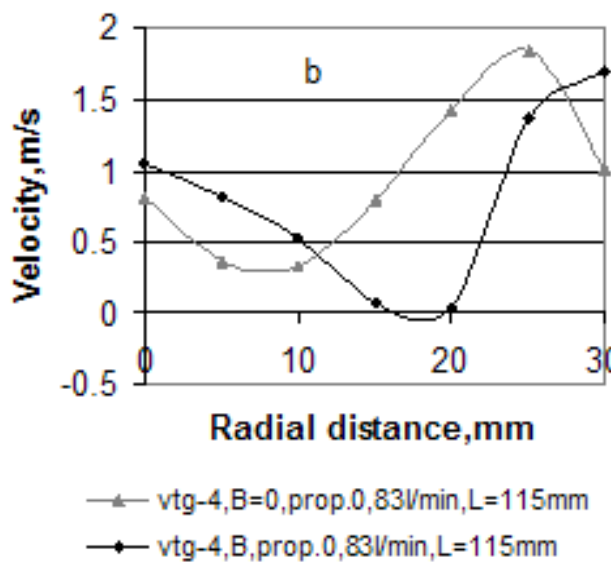

Fig. 7. The magnetic field induced variations of the axial (a) and tangential (b) flame velocity profiles (4: 1000-1200 s).

The axial flow velocity (Fig. 7-a) approaches to the minimum value, promoting the field-enhanced reverse axial mass transfer of the flame species towards the higher magnetic field induction. The field-enhanced radial and reverse axial mass transfer of the paramagnetic oxygen disturbs the shape of the flame velocity profiles, decreasing the axial and tangential flow velocity compounds.

The magnetic field affects the increased rate of $\mathrm{CO}_{2}$ (Fig. 8a) during wood pellet and propane co-firing. This rate correlates with increased combustion efficiency (Fig. 9-a) with a radial expansion of the flame reaction zone and the formation of increased air excess close to the channel walls (Fig. 9-b).

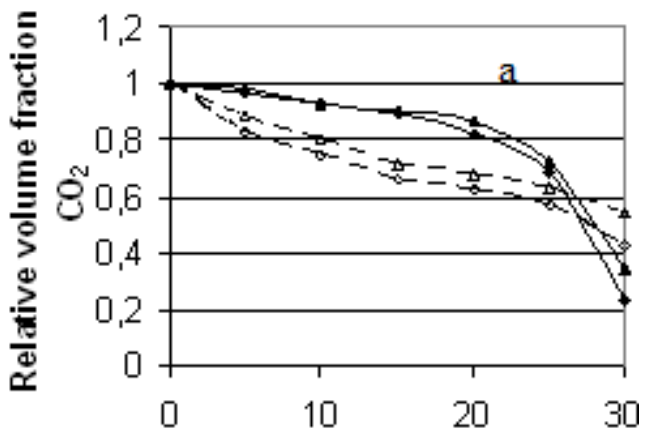

Radial distance, $\mathrm{mm}$
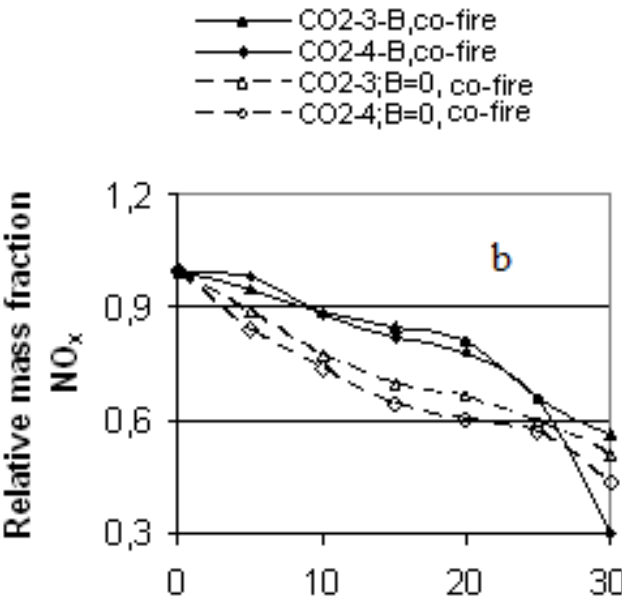

Radial distance,mm

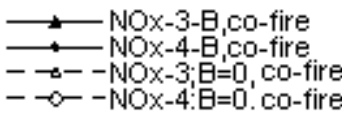

Fig. 8. The formation of $\mathrm{CO}_{2}$ (a) and $\mathrm{NO}_{\mathrm{x}}$ (b) with magnetic field (B) and with magnetic field $(\mathrm{B}=0)(3: 800-1000 \mathrm{~s} ; 4: 1000-1200 \mathrm{~s})$.

An increase of $\mathrm{NO}_{\mathrm{x}}$ emission (at approximately 7\%) production was observed downstream of the swirling flame flow during the wood pellet and propane combustion for conditions, when the magnetic forces acted on the flame (Fig. 8-b). This effect can be related with the slight increase of the flame temperature at about $3 \%$ and the local variations of the free oxygen. 


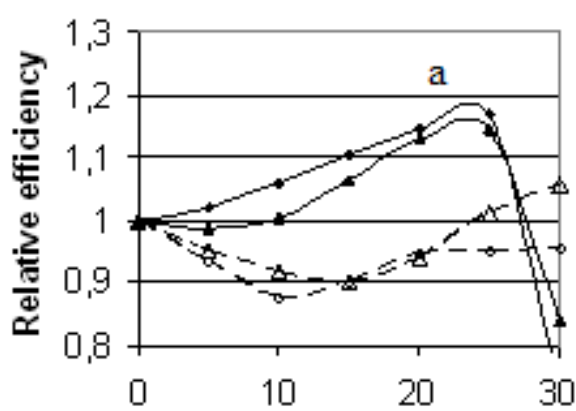

Radial distance, $\mathrm{mm}$
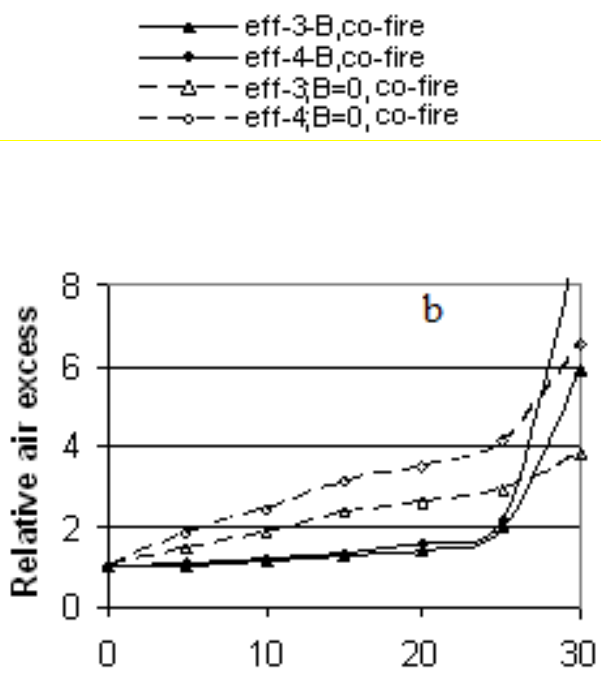

Radial distance,mm

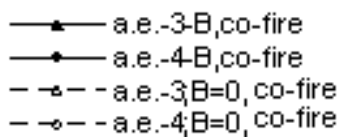

Fig. 9. The relative efficiency (a) and relative air excess (b) for condition when magnetic force is acting on the flame $(\mathrm{B})$ and when is not acting $(\mathrm{B}=0)$ (3: 800-1000 s; 4: 1000-1200 s).

The relative variations of the shape of the flame composition profiles and combustion efficiency have shown that the most pronounced variations are detected along the airside part of the swirling flame flow - in a range from $\mathrm{R}=$ $10 \mathrm{~mm}$ up to $\mathrm{R}=25 \mathrm{~mm}$ (Fig. 8, Fig. 9).

\section{CONCLUSIONS}

Wood pellet and propane co-firing, swirling flow and magnetic field effect on combustion process were investigated as regulation possibilities of biomass combustion. The following conclusions have been drawn from the experimental study:

- During wood pellet and propane co-fire, the use of propane at the primary stage of the combustion process resulted in an increase in the flame temperature, thus enhancing the wood fuel gasification and providing complete burnout of the volatiles, increasing the rate of heat production, combustion efficiency and volume fraction of $\mathrm{CO}_{2}$ in the flame reaction zone. However the increased flame temperature caused the a slight increase in the emission level of NOx during wood pellets and propane co-firing compared to self-sustaining wood pellet combustion. During the co-firing process, the average level of $\mathrm{NO}_{\mathrm{x}}$ was 60-70 ppm.

- The applied magnetic field intensified a paramagnetic oxygen transfer and changed the dynamics of the flame - the tangential and axial velocity distribution of the flame burning area with completing combustion of volatiles. The magnetic field enhanced the mixing of the flame compounds and the combustion of volatiles. The magnetic field affected the increased rate of $\mathrm{CO}_{2}$ during wood pellet and propane co-firing, which correlated with increased combustion efficiency.

- Co-firing and magnetic field could be used as controlling possibilities of the combustion process, providing an increase in the amount of $\mathrm{CO}_{2}$ emissions produced and an increase in the flame temperature and efficiency. One of the problems that could be mentioned is that increased temperatures cause the slight increase of $\mathrm{NO}_{\mathrm{x}}$ emissions.

\section{REFERENCES}

1. Lu H., Scott J., Foster P., et. al. Effects of particle shape and size on devolatilization of biomass particle. Fuel, 2010, vol. 89, N 5, p. 11561168.

2. Barmina I., Gedrovics M., Krishko V., Zake M. Co-firing of the renewable with fossil fuel for the clean and effective heat energy production. Environmental and Climate Technologies, 2009, ser. 13, Nr.2, p. 21-29.

3. Williams A., Jones J.M., Ma L., Pourkashanian M. Pollutants from the combustion of solid biomass fuels, Progress in Energy and Combustion Science, 2012, vol. 38, N 2, p. 113-137.

4. Vassilev S.V., Baxter D., Andersen L.K.., Vassileva C.G. An overview of the chemical composition of biomass, Fuel, 2010, vol. 89, N 5, p. 913-933.

5. Demirbas A. Combustion characteristics of different biomass fuels, Progress in Energy and Combustion Science, 2004, vol. 30, N 2, p. 219 230.

6. Van Loo, S. The Handbook of Biomass Combustion \& Co-firing. UK: CPI Antony Rowe, 2008. 442 p.

7. Villeneuve J., Palacios J.H., Savoie P., Godbout S. A critical review of emission standards and regulations regarding biomass combustion in small scale units (<3MW), Bioresource technology, 2012.

8. Balat M. Mechanisms of Thermochemical Biomass Conversion Processes. Part 2: Reactions of Gasification, Energy Sources, 2008, Part A, N 30, p. 636-648.

9. Reed T.B., Das A. The Handbook of Biomass Downdraft Gasifier Engine Systems. USA: The Biomass Energy Foundation Press, 1988,140 p.

10. Al-Mansour F., Zuwala J. An evaluation of biomass co-firing in Europe Biomass and Bioenergy, 2010, vol. 34, N 5, p. 620-629.

11. Nagaraju K. Study of the effect magnetic field on the properties of combustion synthesized iron oxide nanoparticles. Mg.ing. Thesis, USA: Louisiana State University, 2005, p. 133.

12. Swaminathan S. Effects of magnetic field on micro flames. Mg.ing. Thesis, USA: Louisiana State University, 2005, p. 125. 


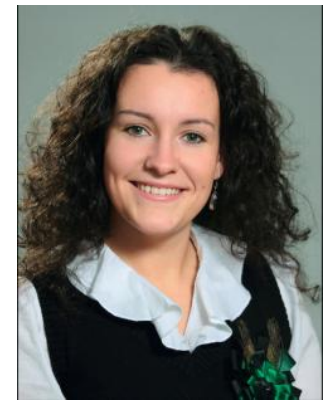

Vera Suzdalenko, Mg.sc., Riga Technical University, Institute of Energy System and Environment. Vera Suzdalenko has been a researcher of the Institute of energy system and environment since 2010. She has a Master degree (2009) and she is $\mathrm{PhD}$ student of RTU Institute of Energy System and Environment. The main research area is the investigation of renewable and fossi fuel co-firing and magnetic field effect on swirling combustion. Vera Suzdalenko participates in local and international conferences. She is the co-author of 11

scientific papers.

Address: Kronvalda blvd. 1, LV-1010, Riga, Latvia

Phone: +371 29719715

E-mail: Vera.Suzdalenko@rtu.lv

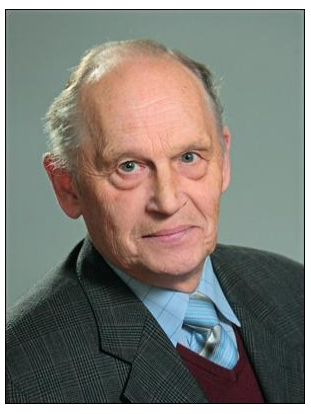

Martins Gedrovics, Dr.sc.ing., professor Riga Technical University, Institute of Energy Systems and Environment. Professor Martins Gedrovics is working within the Faculty of Energy and Electrotechnics, Riga Technical University since 1970 . The main research area is combustion of biofuels. He has participated in different local and international projects related to energy and environment. $\mathrm{M}$. Gedrovics is author of about 80 publications. M. Gedrovičs has Thermal Engineer Diploma (1967) and doctoral degree (1997).

E-mail: martins.gedrovics@rtu.lv

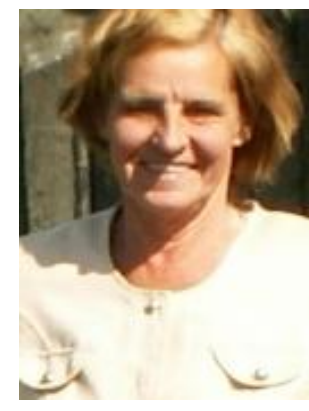

Maija Zake, Dr.phys., University of Latvia, Institute of Physics. Maija Zake has been a leading researcher of the Heat and mass transfer laboratory of Institute of Physics since 1991. PhD promotion - thesis "Electrical conductivity of two phase and two component's system" (1992). The main research areas - gasification and combustion of renewable fuels, co-firing of renewable with fossil fuels, external electric, magnetic and electromagnetic field effects on combustion of renewable. Maija Zake is the co-author of 220 papers and 2 monographs, since 2005 co-author of 18 scientific papers and co-author of 10 presentations in International conferences. Maija Zake is co-author of a patent "Boiler for co-firing of renewable with fossil fuel" (2005) and research leader of Latvian grants from 1991 up to 2006, coordinator of ERAF projects VPD1/ERAF/CFLA/05/APK/2.5.1./000001/001, 20062008 and Nr.2010/0241/2DP/2.1.1.1.0/10/APIA/VIAA/006,2010-2013.

E-mail: $\underline{\text { mzfi@sal.lv }}$

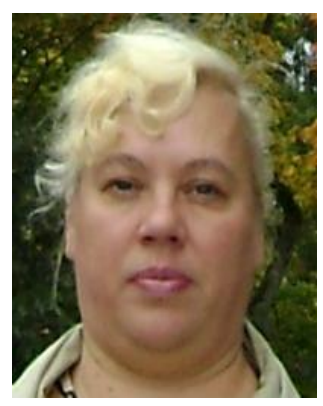

Inesa Barmina, Dr.sc.ing., University of Latvia, Institute of Physics. Inesa Barmina is a leading researcher of Heat and mass transfer laboratory of Institute of Physics, University of Latvia since 2004. PhD thesis "Investigation of external electrical field effects on swirling combustion" (2003). The main research area is experimental study of co-firing the renewable with fossil fuel and external (electric, magnetic, electromagnetic) field effects on swirling combustion. Since 2004 Inesa Barmina is the leading researcher of Latvian grants and ERAF projects: VPD1/ERAF/CFLA/05/APK/2.5.1./ 000001/001, 2006-2008 and Nr.2010/0241/2DP/2.1.1.1.0/10/APIA/VIAA/ 006, 2010-2013. She is coauthor of more than 60 scientific papers. She is co-author of 8 presentations in International conferences since 2005. Inesa Barmina is co-author of patent "Boiler for co-firing of renewable with fossil fuel" (2005)

E-mail: barmina@sal.lv 